\title{
Temperament of Track Cyclists and Their Stress of During a Sports Performance
}

Authors' contribution:

A) conception and design of the study

B) acquisition of data

C) analysis and interpretation of data

D) manuscript preparation

E) obtaining funding
Aleksandra Samełko ${ }^{\mathrm{A}, \mathrm{C}, \mathrm{D}}$, Grzegorz Tomaszewski ${ }^{\mathrm{A}-\mathrm{C}}$

Józef Pitsudski University of Physical Education in Warsaw, Poland

\section{ABSTRACT}

The aim of the study was to evaluate the correlation between temperament and stress, to assess the stress level and perform comparative analysis of feeling of stress before and after the race. The test group consisted of 30 competitors from Mazovian cycling clubs between the ages of 15 and $16(\mathrm{M}=15.5, \mathrm{SD}=0.50)$. Standard psychological questionnaires were used for the study. The level of stress was tested using the PSS 10 questionnaire by S. Cohen, T. Kamarck and R. Mermelstein. In addition, temperament was studied with Formal Characteristics of Behaviour - Temperament Inventory by Zawadzki and Strelau (1997). Measures were used to determine the constant predisposition of cyclists to feel the level of stress, as well as to show the intensity of stress during sports competitions (before and after the start). Statistical analyses carried out with the Wilcoxon test showed a significant difference between the initial and final value of the stress level as a condition in the subjects. It was found that in the same people, stress reached a higher average level after the race $(M=17.8, S D=6)$ than before the performance $(M=11.83, S D=5.9)$. The results show that the state of stress does not decrease after the start, as occurs with other variables (including emotional arousal). The results showed that stress measured before and after the start of a competition positively correlates with perseverance and emotional reactivity, while stress before the start negatively correlates with briskness. Observations from the analyses carried out may broaden the understanding of the phenomenon of stress, especially in aspects of sport competition and track cyclists.

stress, temperament, track cyclists, sports competition

\section{Introduction}

Temperament is relatively constant; it is a property of the nervous system. Among psychological traits temperament is particularly important. Temperament traits are a factor modifying the perceived state of stress depending on the stimulus value of the situation. Temperament determines the optimal level of activation and the severity of negative emotions (Strelau, 1998, pp. 43-44). Depending on one's temperament traits, the source of stress for athletes can be both excess and deficiency of stimulation (Bołdak \& Guszkowska, 2013, p. 197).

Unchanging temperament features determine predispositions for a given type of activity and individual preferences. In sport, athletes are expected to be in great demand for stimulation. High endurance and activity as well as low emotional reactivity are probably properties that allow one to achieve the desired results in most 
sports competitions (Strelau, 1997). The concept used in this work derives from Strelau's Regulatory Temperament Theory.

Temperament is considered a mediator in the perception of affective states and is even associated with the occurrence of affective disorders (Jankowski, 2012, p. 734). Research shows the relationship between temperament characteristics and feeling stress (and coping styles with excessive load (Compas, Connor- Smith \& Jaser, 2004, p. 21). Blecharz and Siekańska believe that temperament mediates stress in competitive sports (2007, pp. 143-156). According to other researchers, temperament directly affects the feeling of stress and coping with difficult situations (Reuda \& Rothbart, 2009, p. 19).

Stress as a ubiquitous element of everyday life has a place in the sport of children and youth. Sports competition is an example of a real event in which one can study people's reactions to stressful situations (Nicolas \& Jebrane, 2008 , p. 735). In physical activity, the concept of stress can be understood in the three most common ways. One of them is a situational stimulus (Holmes \& Rahe, 1967, pp. 213-216).

An example of stressors is the high level of competition, a difficult opponent or high expectations set by the social environment. In studies related to determining the dominant sources of stress among elite competitors and those without the highest scores, stressors related to performance (effect) in competitions are mentioned (Mellalieu et al., 2009, p. 729).

In another concept (Seyle, 1955, pp. 625-660), stress is called special reactions of the organism. Gould, Jackson and Finch (1993, p. 134), when researching figure skaters, asked about the players' thoughts, but also about physical reactions (such as butterflies in the stomach, tremors or nervous sweating).

An important role is played by the ability to cope with cognitive anxiety manifested in intrusive thoughts and somatic anxiety, the symptoms of which are body aches such as abdominal pain or excessive muscular tremor (Łuszczyńska, 2014, pp. 36-48).

The third and the most frequently quoted theory of stress relates to transactions between the resources of an individual and the requirements flowing from the environment (Lazarus \& Folkman, 1984, pp. 100-290). It is directly related to the subjective and unique experiences of the individual. In other analyses carried out with the participation of athletes, the following properties are mentioned: novelty, predictability, event uncertainty, imminence, duration, temporal uncertainty, ambiguity and timing in relation to the life cycle (Thatcher \& Day, 2008, p. 318). Due to the similarity of stress symptoms and among other things overtraining, it is difficult to determine unequivocally what sports stress is and what it is not (De Francisco et al., 2016, p. 239).

Some authors argue that in sports, too much stress can also contribute to overtraining. People can be overwhelmed with stress, and as a result they cannot find time to recover properly or adopt more effective strategies to deal with the situation (Kellmann, 2010, p. 95).

Stress is considered a combination of internal and external pressures that negatively affect the well-being of the subject. Sports competitions create a safe arena for stress management training. Sports competition is in turn a natural phenomenon conducive to increasing efficiency. The competition promotes the occurrence of a facilitation effect (Graydon \& Murphy, 1995, p. 265), where the competitor should demonstrate relatively wellmastered skills. An uncomfortable feeling of stress causes that the body does not behave in a standard or automatic manner, which hinders sports performance and may be a reason for lowering sports results (Nowicki, 2004). In some reports on elite rowers, stress was found to be decisive for optimal performance (Kellmann \& Klaus-Dietrich, 2000, p. 676).

The theories of stress are not mutually exclusive and co-create a complementary description of the mechanism of stress. The authors of the Stress Scale - a tool used in the study - tended to consider the phenomenon of stress as a reaction to a given event. Stressful circumstances should cause strong negative emotions (Sheldon, Kamarck \& Mermenstein, 1983, p. 385; Juszczyński \& Ogińska-Bulik, 2009). 
Researchers tend to consider the relationship between stress and temperament in terms of various sports. Stress researchers found that performance-related stressors include preparation, superstitions, injury, pressure, opponents, self, and events (Hanton, Fletcher \& Coughlan, 2007, p. 1129).

Despite extensive research into the issue of stress in sport, theoreticians do not find a direct impact of stress on performance in sports competitions (Woodman \& Hardy, 2001, p. 207). At the same time, stress is defined as the result of various activities related to sporting activities. According to research, players' overall experience is the most important in the context of stress feeling intensity (Noblet \& Gifford, 2002, p. 1). The phenomenon of stress occurs not only in the circumstances of the competition, but is also associated with training and lack of sufficient regeneration of the body. By constantly experiencing excessive stress associated with the monotony of effort in the absence of rest, the player may feel burnout and overtraining (Kellmann, 2010, p. 95).

Modern analysis proves the relationship between stress and other factors. The findings indicate that higher fear of failure is associated with a positive correlation with psychological stress in athletes (Gustafsson, Sagar \& Stenling, 2017, p. 2091).

Another study measuring the relationship between stress and sports performance among modern pentathletes before their participation in each start showed a negative correlation in the stress-sports results relationship (Samełko \& Guszkowska, 2016, pp. 21-23). Stress is a phenomenon that is eagerly written about in articles devoted to problems affecting athletes (Markser, 2011, p. 182), but at the same time it is difficult to find papers describing the actual measurement of mental stress during sport competition, beyond generalization. It is still difficult to find current research measuring emotional and stress reactions after the performance. In a study of tennis players' stress, the results showed that stress levels were higher for players who lost the match (Filaire et al., 2009, p. 150). An aspect to consider is also the coach, who can be a factor in stressing an athlete (Thelwell \& Neil, 2008, p. 905).

A study conducted with taekwondo players measured the POMS mood and stress before and after the competition (Choido, 2011, p. 111). Such studies are, however, rare in the literature on the subject.

The level of stress is low in studies conducted in adult amateurs. However, we are talking about recreational training, not a high performance in which the best seniors in a given discipline already perform (Eime et al., 2013, p. 1). Reports show that teenagers who insist on sport have fewer emotional problems, and generally feel a higher level of well-being, which translates into less perceived stress in adolescents (Donaldson \& Ronan, 2006, p. 369).

Cycling is a specific sport discipline. Cycling track competitors are a specific group because there are accidents on the track. The fall of one player can decide on the course of the whole race. This undoubtedly results in an increased level of perceived stress during the competition.

The aim of the study was to assess the relationship between a constant temperament level and a situationdependent level of stress. In addition, the goal was to measure the intensity of stress levels before and after the cycling race in the context of current knowledge that the climax of emotional tension is at the highest level just before the start. Emotions seen as affective states accompany stress. According to the theory of emotional arousal, pre-start tension is highest within an hour before the race, reaches a maximum just before the start and decreases with the beginning of the start (Gracz \& Sankowski, 2007, pp. 213-215). Based on the knowledge of affective phenomena, it is suspected that stress should also dominate before the start of a sports competition and be definitely lowered immediately after the race.

In the study three research questions are addressed:

1) What intensity of temperament traits do the track cyclists present?

2) Are there statistically significant correlations between the level of stress tested before and after the race and temperament scales?

3) Is the stress level significantly different before and after the race? 


\section{Methods}

\section{Measures}

To measure the temperamental properties a questionnaire by B. Zawadzki and J. Strelau (1997) was used. Formal Characteristics of Behaviour - Temperament Inventory contains 6 scales: Briskness, Perseverance, Sensory Sensitivity, Emotional Reactivity, Endurance, Activity. The questionnaire was based on the Regulatory Temperament Theory. It meets the assumptions regarding reliability and accuracy. It consists of 120 items, to which the respondent can answer "yes" or "no".

The stress questionnaire (PSS-10) has been used to measure stress and in investigating the intensity of stress in the recent period. The authors of the original version of the test are S. Cohen, T. Kamarck and R. Mermelstein (1983, p. 385-396). The Polish adaptation was created by Z. Juczyński and N. Ogińska-Bulik (2009). The scale contains 10 questions about the subjective feeling of problems and personal events in recent times and measures the response to the stressors of the individual. The questionnaire is short and thus appropriate to the organizational conditions prevailing before the race and just after its completion.

For the purposes of the tests, the instruction was matched to the sports race and contained information referring not to the last month, but to the current state. The respondent types the answers on a 0-10 scale, specifying the frequency of feelings in problem situations and how to deal with them. The scale has sten standards. Relevance and reliability of the test are sufficient for the needs of scientific research.

\section{Participants and procedure}

The test group consisted of licensed track competitors from Mazovian cycling clubs -30 boys between the ages of 15 and $16(\mathrm{M}=15.5, \mathrm{SD}=0.50)$. Each player had a 2-year sports experience and represented the average national level. The research procedure was conducted in two steps. In the initial stage of the research, in neutral conditions, the athletes were informed about the basic purpose of the research and the course of the study. At that time, the competitors filled out the temperament questionnaire. Researchers were given permission from the legal guardians of the boys. The next stage of the study involved the young people filling out stress questionnaires just before the race and the second time after finishing it. Measurement of stress before and after the competition took place in accordance with the literature (Gracz \& Sankowski, pp. 212-224), in which the peak of emotional arousal occurs within an hour before the start until the start of the race. The second measurement was carried out as soon as the competitor finished the race (within the required time of one hour) (2007).

The place for cycling is an indoor track with a distance of 250 meters. It consists of two turns, which in the steepest place are inclined at an angle of 42 degrees. These turns are connected by two straight lines with a much smaller angle of inclination. It is a full-fledged, full-scale track on which European and world-wide competitions take place.

\section{Results}

Statistical analyses for the needs of the research were carried out in Statistica version 12. The methods used were by Wilcoxon's test to compare paired stress results as a condition and by Spearman's test - carried out to obtain information on significant correlations in constant psychological properties. In the first step of the analysis, they included the temperamental characteristics of the tested cyclists. Table 1 presents the percentage values of raw results in individual scales. 
Table 1. Level of average percentage results of temperamental feature (\%)

\begin{tabular}{lllllll}
\hline $\begin{array}{l}\text { Intensity of } \\
\text { the variable }\end{array}$ & $\begin{array}{l}\text { Sensory } \\
\text { Sensitivity } \\
\text { Scale }\end{array}$ & $\begin{array}{l}\text { Emotional } \\
\text { Reactivity } \\
\text { Scale }\end{array}$ & $\begin{array}{l}\text { Activity } \\
\text { Scale }\end{array}$ & $\begin{array}{l}\text { Endurance } \\
\text { Scale }\end{array}$ & $\begin{array}{l}\text { Briskness } \\
\text { Scale }\end{array}$ & $\begin{array}{l}\text { Perseverance } \\
\text { Scale }\end{array}$ \\
\hline Low & 33 & 37 & 10 & 20 & 27 & 23 \\
Medium & 57 & 47 & 77 & 63 & 43 & 53 \\
High & 10 & 17 & 13 & 17 & 30 & 23 \\
\hline
\end{tabular}

Source: own study.

The first table presents the obtained values of the distribution of a given feature in the study group. It was found that the average results in athletes dominate in all variables. The respondents present the advantage of low and average results in the scales of sensory sensitivity and emotional reactivity. The highest number of competitors also shows average norms in the scales of activity, endurance and perseverance. Only on the scale of briskness are the cyclists characterized by the advantage of medium and high scores.

Table. 2. Correlations between stress levels and temperament scales

\begin{tabular}{llll}
\hline Variables & Perseverance & Briskness & $\begin{array}{l}\text { Emotional } \\
\text { Reactivity }\end{array}$ \\
\hline Stress before start & 0.534 & -0.614 & 0.530 \\
Stress after start & 0.488 & & 0.494 \\
\hline
\end{tabular}

$* p<0.05$

Source: own study.

The second table presents the relationship between stress measured before and after the race with individual temperament scales. The results show significant, but moderate, relationships in emotional reactivity, perseverance and briskness scales. It was found that the higher the competitor perseverance, the higher his stress level before and after the start. Similarly, a positive relationship is revealed in the case of emotional reactivity. Briskness, in turn, negatively correlates only with the level of stress before the start.

Table. 3. Internal correlations of studied temperament scales

\begin{tabular}{lllll}
\hline Scale & Endurance & $\begin{array}{l}\text { Sensory } \\
\text { Sensitivity }\end{array}$ & $\begin{array}{l}\text { Emotional } \\
\text { Reactivity }\end{array}$ & Activity \\
& & & \\
\hline Endurance & & & -0.621 & \\
Briskness & 0.424 & 0.399 & -0.368 & \\
Perseverance & -0.588 & & 0.633 & -0.374 \\
\hline$* p<0.05$ & & & &
\end{tabular}

Source: own study.

The study additionally measured correlations inside the temperament scales in the studied group of track cyclists. Table 3 shows only statistically significant relationships between the studied scales in the temperament questionnaire. Spearman's test showed that the persons presenting a higher level of sensory sensitivity were also characterized by an increased level of briskness. In the case of emotional reactivity, the higher the level of the feature, the lower the strength and briskness, but the greater the perseverance. The strength scale showed a positive correlation with the scale of briskness. More perseverant players have a reduced level of activity and 
endurance. The lack of scale in the table indicates that there are no significant differences in correlations with other temperature properties.



Figure 1. Comparison of stress levels before and after the race

Source: own study.

The analyses carried out with Wilcoxon's test show the occurrence of significant differences between two stress state measurements $(Z=3.808, p=0.00014)$. This means that there are significant differences between the stress experienced before and after the race. The results obtained indicate a higher intensity level of stress after the race.

\section{Discussion}

Three research questions were presented in the paper. The first of these concerned the intensity of individual temperament traits in the studied group. The group of cyclists is characterized by a predominance of average values in individual temperament scales. First of all, it concerns the scales of activity, endurance and perseverance. The fact should be taken into account that there is no consistent temperament and reactivity to stress that would characterize all athletes, because the choice of such activities is influenced by various variables, including personal, social and geographical (Monasterio et al., 2016, p. 289). In the case of the scales of sensory sensitivity and emotional reactivity, medium and low scores dominate, which is natural result for athletes (Bołdak \& Guszkowska, 2013, p. 197). Cyclists are predominantly average and high performers only on the briskness scale.

By responding to the second research question regarding the correlation between the level of stress tested before and after and individual temperament scales, the conducted research showed positive correlations between the initial value of stress and perseverance and emotional reactivity. This is not a surprising result and indicates that the cyclists with a higher level of temperamental traits responsible for greater sensitivity and emotionality experienced present a higher level of stress. In the pre-start stress study, it was found that briskness was correlated negatively with pre-race stress. Similar significant relationships were found in the analysis between temperament scales and post-start stress. In the case of perseverance and emotional reactivity, the interdependence was almost at the same level.

The third research question was "is the level of stress significantly different before and after the race?" The results obtained in this study seem surprising. The results of the study show an increased level of stress after the 
performance in relation to the value before the race. This is an unusual situation; in the literature on the subject there is a model of emotional arousal, in which the top level of emotional tension occurs just before the start (Gracz \& Sankowski, 2007, pp. 213-215).

Studies conducted on martial arts players showed an increase in stress hormones, but also in the POMS profile, an increase in anger and depression 30 minutes after the start. Interestingly, at this time the concentration of stress was the highest in the tested players (Choido et al., 2011, p. 111).

Such a result may indicate unusual situations that occurred during the race. During the competition there was an accident that could have increased stress levels after the race. Also, strong light illuminating the entire cycling track could have contributed to the increase in stress levels after the start. In current research on emotions, it is difficult to set a border and simplify the relationship between emotions and action (McCarthy, 2011, p. 50). An increase in arousal, including the feeling of an increased level of stress just after the start, may be evidence of difficult situations that occurred during the course of the race. Taking into account the coping strategies in a difficult situation, there may have occurred a defense mechanism - displacement (Nicolas \& Jebrane, 2009, p. 229) - which made it easier for athletes to operate effectively without experiencing cognitive fear of the start. Denying the feeling of stress is sometimes considered a positive response to a threatening situation that allows one not to think about the problem (Rueda \& Rothbart, 2009, pp. 22-25).

We do not know the specifics of the training of the tested cyclists. Better functioning before the start is shown by people permanently working with a sports psychologist (Birrer \& Morgan, 2010, p. 80). They are taught how to optimize functioning, which can positively affect the reduction of excessive stress. At the same time, some theorists point out that stress in sport is not surprising or endemic (it does not have to occur) (Hanton, 2005, p. 1129). They assume that this is an inherent element of sportsmen's activity and therefore does not occur in extreme intensity.

In addition, another study shows that stress and emotions are highly related structures, which are also associated with satisfaction with the results (Nicholls, Polman \& Levy, 2012, p. 263). In our study, we did not check sports results or subjective satisfaction of competitors.

In other reports related to emotional state tests before and during the match in the case of hockey players, subjects reported a higher level of irritability but less tension during the competition than before the start (Jones, Mace \& Williams, 2000, p. 691). Similarly, anxiety and fear were measured before the competition, and then after the start (Ciucurel, 2012, p. 385).

Studies showing positive correlations between affective arousal and athletic performance in swimmers confirm that it is important to gain better insight into pre-competitive emotional states (Samełko, Guszkowska \& GalaKwiatkowska, 2018, p. 21-24). Our research additionally shows the need to analyze stress and affective states both before and after sports starts.

Only two people from the subjects had high levels of stress before the start. These people were characterized by an increased level of emotional reactivity in relation to other cyclists. After the race, an elevated level of stress was also presented by players with low emotional reactivity.

Some studies show that the negative emotions experienced before the performance affect the sports result badly (Neil et al., 2011, p. 460). Feeling negative emotions is interpreted as debilitating results. Therefore, it may be targeted with remedial strategies applied by high-performance athletes. Probably due to the fact that the athletes whom we examined were a homogeneous group with regard to discipline, sex and age our statistical results turned out to be quite strong. 


\section{Conclusion and practical implications}

The results of our research contrast with the current knowledge pertaining to the state of emotion (Gracz \& Sankowski, 2007, pp. 207-224) where the peak moment of emotional arousal occurs just before the start and a reduction takes place at the beginning of the competition and steadily subsides after the competition. The results of the research may also indicate the defense mechanism (stress feelings in the group of adolescents may interfere with the optimal preparation for a competition) (Nicolas \& Jebrane, 2009, p. 229). The analyses did not take into account the effectiveness of the tested cyclists. In the Fletcher and Fletcher model (2005, p. 157), the relationship between stress, emotions and performance was described. Perhaps future research should include information related to the results obtained in the competition to create a complementary study.

Research shows that stress of track cyclists is higher at the end of the race than before the start of the race. This may be the reason for completely different work at the mental level where the moment before the start does not count so much, but with the creation of optimal coping strategies during the start.

\section{Ethics approval and informed consent}

The research was conducted with the written informed consent of the competitors and their legal guardians.

\section{Competing interests}

We declare that there is no conflict of interest.

\section{Funding}

The study was conducted from the authors' own sources.

\section{REFERENCES}

Blecharz, J., \& Siekańska, M. (2007). Temperament structure and ways of coping with stress among professional soccer and basketball players. Biology of Sport, 24(2), 143-156.

Birrer, D., \& Morgan, G. (2010). Psychological skills training as a way to enhance an athlete's performance in high-intensity sports. Scandinavian Journal of Medicine \& Science in Sports, 20(2), 78-87.

Bołdak, A., \& Guszkowska, M. (2013). Are Skydivers a Homogenous Group? Analysis of Features of Temperament, Sensation Seeking, and Risk Taking. The International Journal of Aviation Psychology, 23, 3, 197-212. DOI: https://doi.org/10.1080/10508414.2013.799342

Choido, S., Tessitore, A., Cortis, C., Cibelli, G., Lupo, C., Ammendolia, A., De Rosas, M., \& Capranica, L. (2011). Stressrelated hormonal and psychological changes to official youth Taekwondo competitions. Skandinavian Journal of Medicine \& Science in Sports, 21,1,111-119. DOI: https://doi.org/10.1111/j.1600-0838.2009.01046.x

Ciucurel, M.M. (2012).The relation between anxiety, reaction time and performance before and after sport competitions. Procedia-Social and Behavioral Sciences, 33, 885-889.

Cohen, S., Kamarck, T., \& Mermelstein, R. (1983). A global measure of perceived stress. Journal of Health and Social Behavior, 24, 385-396.

Compas, B.E., Connor- Smith, J. \& Jaser, S.S. (2004). Temperament, Stress Reactivity, and Coping: Implications for Depression in Childhood and Adolescence. Journal of Clinical Child \& Adolescent Psychology, 33(1), 21-31.

De Francisco, C., Arce, C., del Pilar Vílchez, M., \& Vales, A. (2016). Antecedents and consequences of burnout in athletes: Perceived stress and depression. International Journal of Clinical and Health Psychology,16(3), 239-246.

Donaldson, S.J., \& Ronan, K.R. (2006).The effects of sports participation on young adolescents' emotional well-being. Adolescence, 41(162), 369-389.

Eime, R.M, Young, J.A., Harvey, J.T., Charity, M.J., \& Payne, W.R. (2013). A systematic review of the psychological and social benefits of participation in sport for adults: informing development of a conceptual model of health through sport. International Journal of Behavioral Nutrition and Physical Activity, 10 (135), 1-14. 
Filaire, E., Alix, D., Ferrand, C., \&Verger, M.(2009). Psychophysiological stress in tennis players during the first single match of a tournament. Psychoneuroendocrinology, 34(1), 150-157.

Fletcher, D., \& Fletcher, J. (2005). A meta-model of stress, emotions and performance: Conceptual foundations, theoretical framework, and research directions [Abstract]. Journal of Sports Sciences, 23, 157-158.

Gould, D., Jackson, S.A., \& Finch, L.M. (1993). Sources of stress in national champion figure skaters. Journal of Sport and Exercise Psychology, 15, 134-159.

Gustafsson, H., Sagar, S.S., \& Stenling, A. (2017). Fear of failure, psychological stress, and burnout among adolescent athletes competing in high level sport. Scandinavian Journal of Medicine \& Science in Sports, 27 (12), 2091-2102. DOI: https://doi.org/10.1111/sms.12797

Gracz, J., \& Sankowski, T. (2007). Psychologia aktywności sportowej /Psychology of sport activity/. Poznań: Wyd. AWF. Graydon, J., \& Murphy, T. (1995). The effect of personality on social facilitation whilst performing a sports related task. Personality and Individual Differences, 19(2), 265-267.

Hanton, Sh., Fletcher, D., \& Coughlan, G. (2007). Stress in elite sport performers: A comparative study of competitive and organizational stressors. Journal of Sports Sciences, $23 \quad(10), \quad 1129-1141 . \quad$ DOI: https://doi.org/10.1080/02640410500131480

Holmes, T.H. \& Rahe, R.H. (1967). The Social Readjustment Rating Scale. Journal of Psychosomatic Research, 11, $213-$ 218.

Jankowski, K.S. (2012). Morningness-eveningness and temperament: The Regulative Theory of Temperament perspective. Personality and Individual Differences, 53(6),734-739.

Jones, M.V, Mace, R.D., \& Williams, S. (2000). Relationship between Emotional State and Performance during International Field Hockey Matches. Perceptual and motor skills, 90(2), 691-701.

Juszczyński, Z., \& Ogińska-Bulik, N. (2009). Narzędzia pomiaru stresu i radzenia sobie ze stresem /Tools for measuring stress and coping with stress/. Warszawa: PTP.

Kellmann, M., \& Klaus-Dietrich, G.(2000). Changes in stress and recovery in elite rowers during preparation for the Olympic Games. Medicine\& Science in Sports \& Exercise, 32(3), 676-683.

Kellmann, M. (2010). Preventing overtraining in athletes in high-intensity sports and stress/recovery monitoring. Scandinavian Journal of Medicine \& Science in Sports,20(2), 95-102

Lazarus, R.S., \& Folkman, S. (1984). Stress, apprisal and coping. New York: Springer

Łuszczyńska, A. (2014). Psychologia sportu i aktywności fizycznej. Zagadnienia kliniczne /Psychology of sport and physical activity. Clinical issues/. Warszawa: PWN.

Markser ,V.Z. (2011). Sport psychiatry and psychotherapy. Mental strains and disorders in professional sports. Challenge and answer to societal changes. European Archives of Psychiatry and Clinical Neuroscience, 261,2, 182-185.DOI: 10.1007/s00406-011-0239-x

McCarthy, P. (2011). Positive emotion In sport performance: current status and future directions. International Review of Sport and Exercise Psychology, 4(1), 50-69.

Mellalieu, S.D, Neil, R., Hanton, Sh., \& Fletcher, D. (2009). Competiton stress in sport performers: Stressors experienced in the competition environment. Journal of Sport Science, 27(7),729-744.

Monasterio E., Mei- Dan, O., Hackney, C., Lane, R., Rozsa, S. \& Cloninger, R. (2016). Stress reactivity and personality in extreme sport athletes: The psychobiology of BASE jumpers. Physiology \& Behavior, 167, 289-297.

Neil, R., Hanton, Sh., Mellalieu, S. D., \& Fletcher, D. (2011). Competition stress and emotions in sport performers: The role of further appraisals. Journal of Sports Science, 12(4), 460- 470.

Nicolas, M., \& Jebrane, A. (2009). Consistency of coping strategies and defense mechanisms during training sessions and sport competitions. International Journal of Sport Psychology, 40(2), 229-248.

Nicolas, M., \& Jebrane, A., (2008). Relationships between Coping Strategies and Defence Mechanisms in Sport Performance. Psychological Reports, 103(3),735-744.

Nicholls, A.R., Polman, R.C.J., \& Levy, A.R. (2012). A path analysis of stress appraisals, emotions, coping, and performance satisfaction among athletes. Psychology of Sport and Exercise, 13, 3, 263-270.

Noblet, A. J. \& Gifford, S.M. (2002). The Sources of Stress Experienced by Professional Australian Footballers. Journal of Applied Sport Psychology,14(1),1-13. DOI: https://doi.org/10.1080/10413200209339007

Nowicki, D. (2004). Stres w aktywności sportowej dzieci i młodzieży /Stress in sport activity of children and youth /. In M. Krawczyński \& D. Nowicki (Eds.), Psychologia sportu w treningu dzieci i młodzieży /Sports psychology in training children and youth/(pp.99-116). Warszawa: COS. 
Rueda, M.R., \& Rothbart, M.K. (2009). The influence of temperament on the development of coping: The role of maturation and experience. In E. A. Skinner \& M. J. Zimmer-Gembeck (Eds.), Coping and the development of regulation. New Directions for Child and Adolescent Development, 124, (pp. 19-31). San Francisco: Jossey-Bass.

Samełko, A., \& Guszkowska, M. (2016), Affective states and performance outcomes- the findings of preliminary research involving pentathletes. Polish Journal of Sport and Tourism, 23(1) 21-24.

Samełko, A., Guszkowska, M., \& Gala-Kwiatkowska, A. (2018), Affective states influence sport performance in swimming. Polish Journal of Sport and Tourism, 25 (4), 21-26.

Selye, H. (1955). Stress and disease. Science, 122 (3171), 625-663.

Sheldon, C., Kamarck, T., \& Mermelstein, R. (1983). A Global Measure of Perceived Stress. Journal of Health and Social Behavior, 24(4),385-396.

Strelau, J., \& Zawadzki, B. (1997). Formalna Charakterystyka Zachowania- kwestionariusz temperamentu (FCZKT).Warszawa: PTP.

Strelau, J. (1998). Psychologia temperamentu /Psychology of temperament/. Warszawa: PWN.

Thatcher, J., \& Day, M.C. (2008). Re-apprasing stress appraisals: The underlying properties of stress in sport. Psychology of Sport and Exercise, 9(3), 318-335.

Thelwell, R.C., Weston, N. J.V., Greenlees, I.A., \& Hutchings, N.V. (2008). Stressors in elite sport: A coach perspective. Stressors in elite sport: A coach perspective, 26(9), 905-918. DOI: https://doi.org/10.1080/02640410801885933.

Woodman, T., \& Hardy, L. (2001). A case study of organizational stress in elite sport. Journal of Applied Sport Psychology, $13,207-238$

\title{
AUTHOR'S ADDRESS:
}

\author{
Aleksandra Samełko \\ Department of Physical Education \\ Józef Piłsudski University of Physical Education in Warsaw \\ Marymoncka 34 \\ 00-968, Warsaw \\ Poland \\ E-mail: al.samelko@gmail.com
}

Received: 23 July 2019; Accepted: 14 January 2020 